\title{
The effects of crack on the transmission matrix of rotor systems
}

\author{
Z.K. Peng ${ }^{\mathrm{a}, *}$, Z.Q. Lang ${ }^{\mathrm{b}}$, G. Meng ${ }^{\mathrm{a}}$ and F.L. Chu ${ }^{\mathrm{c}}$ \\ a State Key Laboratory of Mechanical System and Vibration, Shanghai Jiao Tong University, Shanghai, 200240. \\ P.R. China \\ ${ }^{\mathrm{b}}$ Department of Automatic Control and Systems Engineering, University of Sheffield, Mappin Street, Sheffield, S1 \\ $3 J D, U K$ \\ ${ }^{\mathrm{c}}$ Department of Precision Instruments, Tsinghua University, Beijing 100084, P.R. China
}

Received 4 February 2010

Revised 15 April 2010

\begin{abstract}
The dynamic behavior of rotor containing crack is a subject of particular interest and has been extensively investigated by researchers. The effects of crack on the natural frequencies and modal shapes and motion orbits of rotor systems have already been well explored by researchers. In the present study, the infl uence of crack on the transmission matrices of the rotor systems is investigated by using the FEM (finite element method) analysis and the HBM (harmonic balance method) technique. It is for the first time revealed that there are differences between the transmission matrices for the fundamental frequency components and the transmission matrices for the super-harmonic components, and the differences are mainly determined by the crack location. The results are validated by numerical experiments where the system responses of a rotor system are obtained using Runge-Kutta method. The results are of significance for the development of effective crack detection methods in practice.
\end{abstract}

Keywords: Crack detection, rotor systems, nonlinear vibration, harmonic balance method, transmission matrix

\section{Introduction}

Fatigue cracks are a potential source of catastrophic failure for rotating machines. To understand how the presence of crack in shaft may affect the dynamic behaviours of a rotor system and so to identify the characteristics of a cracked rotor system, various crack models have been established by generally assuming only in the region adjacent to the crack the stress field is affected and therefore effects of crack could be represented by change of the local flexibility coefficients expressed by the stress intensity factor. There are several excellent reviews available on this subject [1-3]. To avoid the failure caused by cracks before it happens, researchers have performed extensive investigations to develop integrity monitoring techniques. Most of the techniques are based on vibration measurement and analysis as in most cases vibration based methods can offer an effective and convenient way to detect fatigue cracks in shafts. By the vibration-based approaches the presences of cracks in a target object are usually detected through the monitoring of changes in critical frequencies [4] or in the vibration signals' fundamental harmonic component or second super-harmonic component [5]. Moreover, it is believed that the second super-harmonic component at half the first critical frequency is a good indicator of the crack, and observing the super-harmonic component during start-up/coast-won is more useful than during steady-state operation [6,7]. In addition, with the advance in signal processing methods, more and more research efforts have been made to extract the signatures of crack from the sampled vibration signals using the now so-called advanced signal processing methods, such as the

*Corresponding author. Tel.: +86 21 34206332, ext. 810; E-mail: pengzhike@tsinghua.org.cn. 


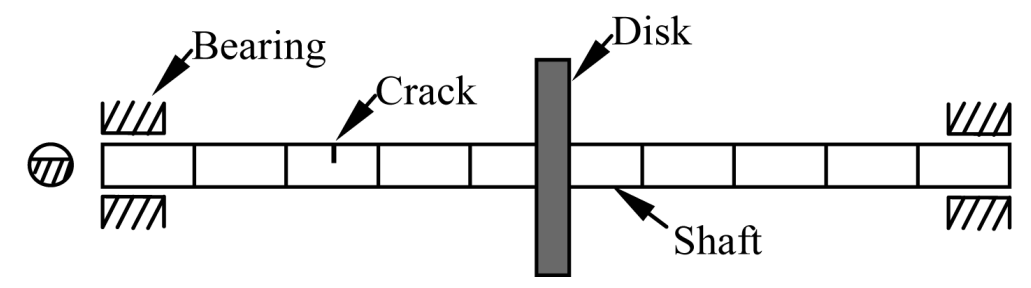

Fig. 1. Rotor system with one cracked shaft.

wavelet transform [8], Wigner-Ville distribution [9] and the Hilbert-Huang transform [10] and et al. Some other crack detection methods include the model-based methods [11], which are usually based on analytical or numerical models to simulate the behavior of cracked shafts during operation and to attempt correlate the observed vibration signature with the presence of a crack at discrete locations on the shaft, and the artificial methods [12,13], in which the problem of crack detection is normally regarded as a pattern reorganization problem and the fault features are often required to be prior extracted from the sampled vibration signals. A comprehensive review, which covers most literature about the crack detection for shaft up to 2003, was contributed by Sabnavis [14] and et al.

While great achievements have been obtained in the study of crack rotors, few efforts have been made to address the issue of how the crack could affect the mechanical impedance [15-19], mobility [15] and transmission matrix [20-22] (to a certain extent, there is an essential likeness between the three conceptions) of rotor systems although it has been found that the mechanical impedance is quite sensitive to the crack in shaft $[17,18]$. The three concepts all originated from the electricity field, according to the investigation by Gardonio and Brennan [15] about the evolution of mobility and impedance methods in structural dynamics. The concepts of mobility and impedance are defined as the complex ratio of the velocity across an element to the force through the element, while the transmission matrix is normally used to describe the relationship between the displacements at the two ends of the element. In this paper, with FEM (Finite Element Method) analysis, the influence of a crack on the transmission matrix of the rotor systems is investigated. Some interesting results are revealed for the first time and they might allow researchers to developed novel method to locate the precise position of the crack in the shaft.

\section{Modeling of the cracked rotor system}

In this section, the FEM method is applied to establish the equation motion for a rotor bearing system [23] that consists of one rigid disk at the mid-span, one cracked shaft and bearings, as shown in Fig. 1.

\subsection{Model of the rotor}

Figure 2 shows the $i^{\text {th }}$ shaft element and the displacements of its two nodes are defined by

$$
\left[u_{(i)}^{\prime}, u_{(i+1)}^{\prime}\right]=\left[x_{(i)}, y_{(i)}, \theta_{x(i)}, \theta_{y(i)}, x_{(i+1)}, y_{(i+1)}, \theta_{x(i+1)}, \theta_{y(i+1)}\right]^{\prime}
$$

According to the well-established finite element method, for the $i^{\text {th }}$ shaft element shown Fig. 2, the expressions of the stiffness matrix $\left[K_{s}\right]^{(i)}$, the skew-symmetric gyroscopic matrix $\left[J_{s}\right]^{(i)}$ and the mass matrix $\left[M_{s}\right]^{(i)}$ can be written as

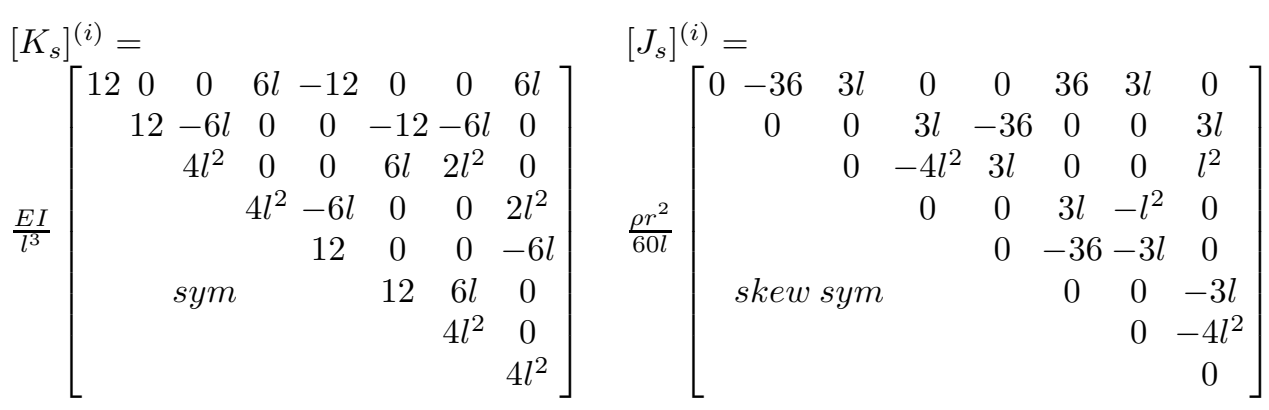




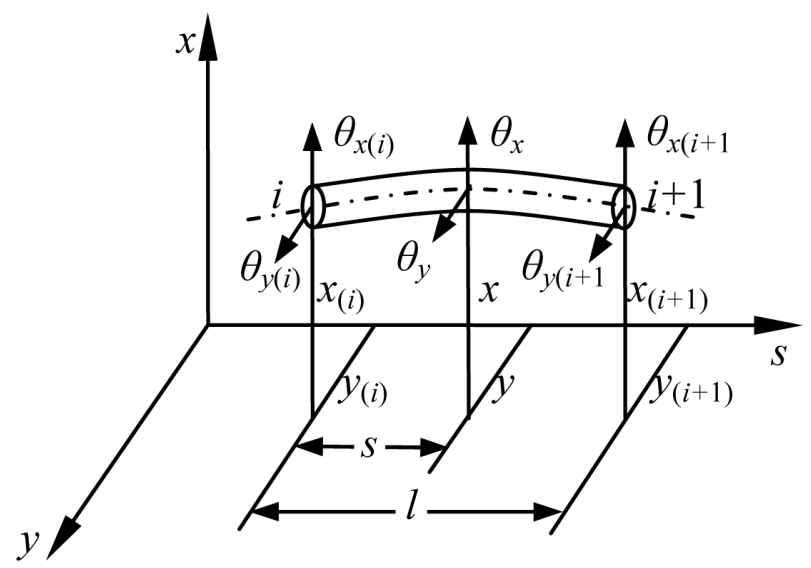

Fig. 2. A shaft finite element.

$$
\left[M_{s}\right]^{(i)}=\left[M_{s T}\right]^{(i)}+\left[M_{s R}\right]^{(i)}
$$

where $E$, $r$ and $\rho$ are the Young's modulus of elasticity, radius and the density of the rotor respectively. $\left[M_{s T}\right]^{(i)}$ and $\left[M_{s R}\right]^{(i)}$ are the translational and rotary mass matrices of the shaft respectively and defined as

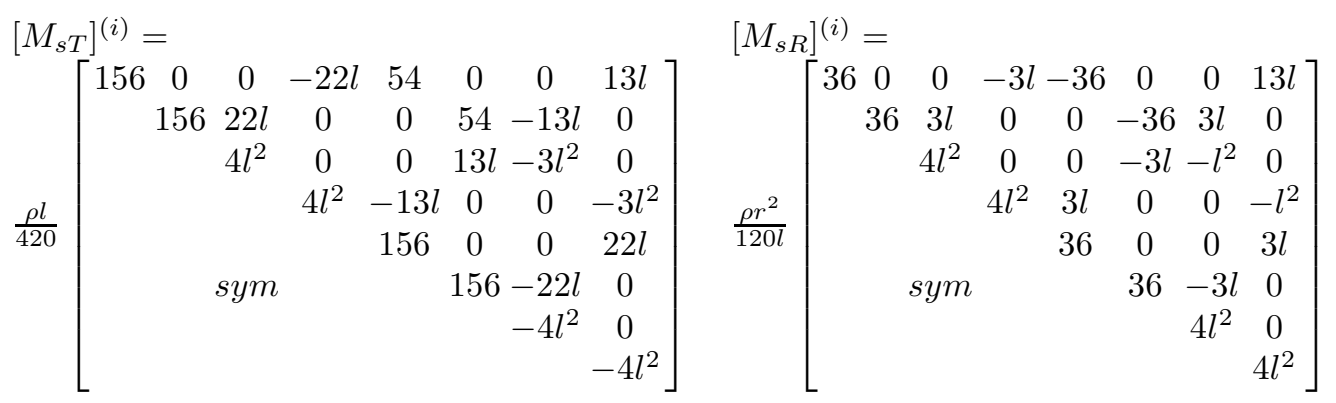

The mass and gyroscopic matrices of the disk corresponding to the degree-of-freedom $\left[x, y, \theta_{x}, \theta_{y}\right]^{\prime}$ are given by

$$
\left[M_{d}\right]=\left[\begin{array}{cccc}
m & 0 & 0 & 0 \\
0 & m & 0 & 0 \\
0 & 0 & I_{d} & 0 \\
0 & 0 & 0 & I_{d}
\end{array}\right] \text { and }\left[J_{d}\right]=\Omega\left[\begin{array}{cccc}
0 & 0 & 0 & 0 \\
0 & 0 & 0 & I_{p} \\
0 & 0 & 0 & 0 \\
0 & -I_{p} & 0 & 0
\end{array}\right]
$$

where $m$ is the mass of the disk and $I_{p}$ and $I_{d}$ are the polar moment of inertia about rotor axis and the diametral moment of inertia about any axis perpendicular to the rotor axis respectively. $\Omega$ is the rotating speed of the rotor.

The mass matrix $\left[M_{s}\right]^{(i)}$, stiffness matrix $\left[K_{s}\right]^{(i)}$ and gyroscopic matrix $\left[J_{s}\right]^{(i)}$ can all be uniformly rewritten as the following block form

$$
\beta^{(i)}=\left[\begin{array}{ll}
{[\beta]_{11}^{(i)}} & {[\beta]_{12}^{(i)}} \\
{[\beta]_{21}^{(i)}} & {[\beta]_{22}^{(i)}}
\end{array}\right]
$$

where $[\beta]_{11}^{(i)},[\beta]_{12}^{(i)},[\beta]_{21}^{(i)}$ and $[\beta]_{22}^{(i)}$ are a matrix of size $4 \times 4$. For a rotor discretized into $N$ Timoshenko beam elements, the mass matrix $M_{s}$ and gyroscopic matrix $J_{s}$, and stiffness matrix $K_{s}$ for the complete rotor can be generated by assembling all the $N$ shaft element matrices using the way described below 


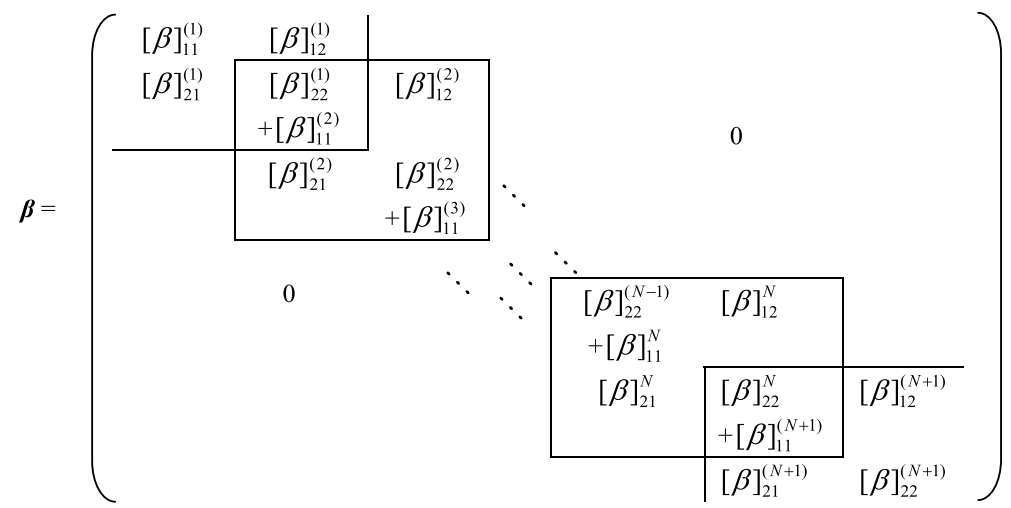

To generate the mass matrix $M$ and gyroscopic matrix $J$, and stiffness matrix $K$ for the complete rotor system including the supporting bearing and the disk, the mass and gyroscopic matrices of the disk element and the stiffness matrix of the bearing element need to be assembled to their corresponding locations in $M_{s}, J_{s}$ and $K_{s}$. For example, assembling the bearing elements at the two ends of the shaft can be done by

$$
[K]_{11}^{(1)}=\left[K_{s}\right]_{11}^{(1)}+\left[\begin{array}{cccc}
K_{b x} & 0 & 0 & 0 \\
0 & K_{b y} & 0 & 0 \\
0 & 0 & 0 & 0 \\
0 & 0 & 0 & 0
\end{array}\right] \text { and }[K]_{22}^{(N)}=\left[K_{s}\right]_{22}^{(N)}+\left[\begin{array}{cccc}
K_{b x} & 0 & 0 & 0 \\
0 & K_{b y} & 0 & 0 \\
0 & 0 & 0 & 0 \\
0 & 0 & 0 & 0
\end{array}\right]
$$

and assembling the disk element at the $D^{\text {th }}$ node of the shaft can be finished by adding $\left[M_{d}\right]$ and $\left[J_{d}\right]$ to the $4 \times 4$ sub-matrix along the diagonal lines of $M_{s}, J_{s}$ respectively whose degree-of-freedom is $\left[x_{(D)}, y_{(D)}, \theta_{x(D)}, \theta_{y(D)}\right]^{\prime}$.

Then the equation of motion for the complete rotor system can be written as follows.

$$
M \ddot{u}+(C+\omega J) \dot{u}+K u=Q
$$

where $C$ is the external damping matrix, and $u=\left[u_{(1)}^{\prime}, \cdots, u_{(N+1)}^{\prime}\right]$, and $Q$ is a $4(N+1) \times 1$ vector defining the imbalance force, which, by ignoring the effect of the gravity force, can be expressed by

$$
Q=m e \omega^{2}[\overbrace{0 \cdots 0}^{4(D-1)} \cos (\omega t) \sin (\omega t) 00 \overbrace{0 \cdots 0}^{4(N-D+1)}]^{\prime}
$$

where $e$ is the eccentricity of the imbalance mass of the disk.

\subsection{Model of opening and closing crack}

The modelling of transverse crack is briefly presented here. To accurately predict the dynamic response of a cracked rotor system, an appropriate crack model is crucial. Many researchers have made great efforts to study this problem. Now a well-recognized way for modelling the effects of crack is the localized additional flexibility method by considering the strain energy density function and the associated crack stress concentration factor. According to the Saint-Venant principle, the crack could only affect the stress filed in the region adjacent to it, and therefore the element stiffness matrix without crack may still be regarded as unchanged under certain limitations of the element size. The additional strain energy of crack has been considered in fracture mechanics, and by means of Castigliano's theorem the flexibility coefficient expressed by the stress intensity factor can be easily derived, and then the flexibility matrix of the cracked element can be calculated. According to Mayes and Davies [24], a transverse crack in shaft might be represented by the reduction of the second moment of area $\Delta I$ of the element at location of the crack. By using Rayleigh's method, the change in $\Delta I$ satisfied

$$
\frac{\Delta I / I_{0}}{1-\Delta I / I_{0}}=\frac{r}{l}\left(1-v^{2}\right) F(\mu)
$$


where $I_{0}$ and $v$ are the second moment of area, the Possion's ratio, $\mu=a / r$ where a defines the crack depth. $F(\mu)$ is the fractional change in the second moment of area measured at the crack face. Using the expressions given in Ref [23], the stiffness matrix of the cracked shaft element, $\left[K_{c}\right]$, can be written as

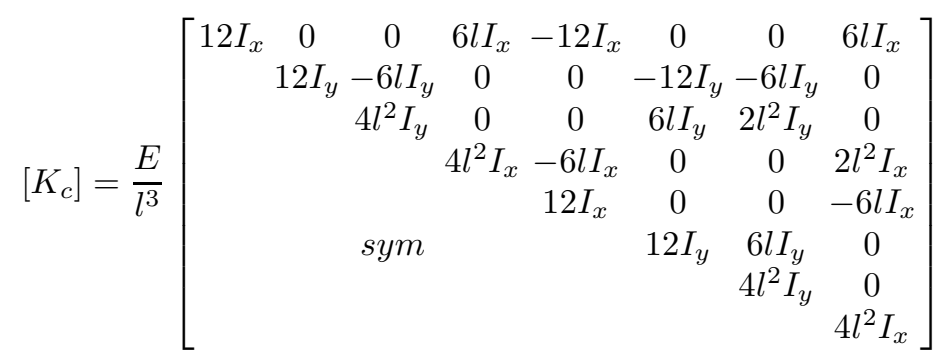

where $I_{X}$ and $I_{Y}$ are the moments of inertia about the $X$ and $Y$ axes, the calculations of which can be found in the appendix of reference [25].

When the crack is assumed to affect only the stiffness, the stiffness matrix of the cracked element, $\left[K_{c}\right]$, is used to replace the stiffness matrix of the element that was originally uncracked when assembling the stiffness matrix of the shaft to generate $K$ in Eq. (8). For a shaft with breathing crack, during the rotation, the system stiffness varies with time or with angle, and the variation may be expressed by a truncated cosine series,

$$
[K]=\left[K_{0}\right]+\left[K_{1}\right] \cos (\omega t)+\left[K_{2}\right] \cos (2 \omega t)+\left[K_{3}\right] \cos (3 \omega t)+\left[K_{4}\right] \cos (4 \omega t)
$$

where $\left[K_{i}\right](i=0,1, \ldots, 4)$, are fitting coefficient matrices. According to Papadopoulos and Dimarogonas [26], these fitting matrices can be determined as follows

$$
\left\{\begin{array}{l}
{\left[K_{0}\right]=\left(5 K_{O P}+5 K_{U C}+6 K_{H C}\right) / 16} \\
{\left[K_{1}\right]=9\left(K_{U C}-K_{O P}\right) / 16} \\
{\left[K_{2}\right]=\left(K_{O P}+K_{U C}-2 K_{H C}\right) / 4} \\
{\left[K_{3}\right]=\left(K_{O P}-K_{U C}\right) / 16} \\
{\left[K_{4}\right]=\left(-K_{O P}-K_{U C}+2 K_{H C}\right) / 4}
\end{array}\right.
$$

where $\left[K_{U C}\right],\left[K_{O P}\right]$ and $\left[K_{H C}\right]$ are corresponding to the uncracked, fully open crack and half-open crack conditions, respectively.

\subsection{Model of the cracked rotor system}

Replacing the stiffness matrix element in $K$, which is corresponding to the crack, with $\left[K_{0}\right]$ and expanding $\left[K_{i}\right]$ $(i=0,1, \ldots, 4)$ to $K$ 's size by padding zero, then the equation of motion for the complete cracked rotor system can be written as follows,

$$
M \ddot{u}+(C+\omega J) \dot{u}+K u+F_{c}=Q(t)
$$

with 515

$$
F_{c}(u, \omega, t)=\left(\sum_{i=1}^{4} K_{i} \cos (i \omega t)\right) u
$$

which can be regarded as an extra periodic force caused by the crack. Assume the $L^{\text {th }}$ element is with crack, then it is easy to know that the periodic force $F_{c}(u, \omega, t)$ can be expressed as the following form, i.e.,

$$
F_{c}(u, \omega, t)=[\overbrace{0 \cdots 0}^{4(L-1)} F_{c}^{(1)}(u, \omega, t) \cdots F_{c}^{(8)}(u, \omega, t) \overbrace{0 \cdots 0}^{4(N-L)}]^{\prime}
$$

The system given by Eq. (14) is a nonlinear system with time varying coefficients. It is known that besides the fundamental harmonic component $1 \mathrm{X}$ which is the frequency of the imbalance force, more super-harmonic components such as $2 \mathrm{X}, 3 \mathrm{X}$ and $4 \mathrm{X}$ et al. will appear in the output response, this phenomenon is often termed as the nonlinear effects [27], and lots of studies have indicated that the nonlinear effects are quite sensitive to the presence 
of crack and can be regarded as the features of crack fault. In addition, the presence of crack could also introduce the secondary resonance to the rotor machines which features as the resonance occurring at half the eigen-frequency of the rotating machines. All those phenomena have already well explored by researchers, as well as how the crack can affect the natural frequencies and modal shapes and motion orbits of the rotor systems, and therefore the focus of this study is the effects of the presence of crack on the transmission matrix of the rotor system, which have not received enough attentions yet.

\section{Transmission matrix of the cracked rotor system}

One of the classical approaches to calculate the system response of the cracked rotor system is the Harmonic Balance Method (HBM) [27], the basic idea of which is quite simple: to substitute a Fourier series form solution of the system time domain response into the governing equations of the nonlinear rotor system, and to equate coefficients of the same harmonic components. Rather than using the HBM to calculate the steady-state response of the cracked rotor system Eq. (14), in this study the HBM will be applied to investigate the effects of crack on the transmission matrix of the rotor system. The transmission matrix [29] is often used to describe the relationship between the displacement vectors at two ends of the shaft element, i.e.

$$
\left[u_{(i)}\right]=\left[T^{(i, i+1)}\right]\left[u_{(i+1)}\right]
$$

Denote the amplitudes of the periodic component at frequency $\Omega$ are $U(j \Omega), F_{c}(j \Omega), Q(j \Omega)$ for $u(t), x(t), F_{c}(u, \omega, t)$ and $Q(t)$ respectively. Applying HBM method to Eq. (14) yields

$$
\left(-M \Omega^{2}+j \Omega(C+\Omega J)+K\right) U(j \Omega)+F_{c}(j \Omega)=Q(j \Omega)
$$

Rewrite $U(j \Omega), F_{c}(j \Omega)$ and $Q(j \Omega)$ as the following block forms, i.e.,

$$
\begin{aligned}
& U(j \Omega)=\left[u_{(1)}^{\prime}(j \Omega), \cdots, u_{(N+1)}^{\prime}(j \Omega)\right]^{\prime}, \quad F_{c}(j \Omega)=\left[F_{c(1)}^{\prime}(j \Omega), \cdots, F_{c(N+1)}^{\prime}(j \Omega)\right]^{\prime} \text { and } \\
& Q(j \Omega)=\left[Q_{(1)}^{\prime}(j \Omega), \cdots, Q_{(N+1)}^{\prime}(j \Omega)\right]^{\prime}
\end{aligned}
$$

where $u_{(i)}(j \Omega), F_{c(i)}(j \Omega)$ and $Q_{(i)}(j \Omega)(i=1, \ldots, N+1)$ are vectors of size $4 \times 1$. Obviously, $F_{c(i)}(j \Omega)=0$ for $i \neq L$ and $i \neq L+1$, and $Q_{(i)}(j \Omega)=0$ for $i \neq D$.

Further denote

$$
\begin{aligned}
& {[\Psi]_{1}^{(i)}=-\Omega^{2}[M]_{21}^{(i)}+j \Omega\left([C]_{21}^{(i)}+\Omega[J]_{21}^{(i)}\right)+[K]_{21}^{(i)}} \\
& {[\Psi]_{2}^{(i)}=\left[\begin{array}{l}
-\Omega^{2}\left([M]_{22}^{(i-1)}+[M]_{11}^{(i)}\right)+[K]_{22}^{(i-1)}+[K]_{11}^{(i)} \\
+j \Omega\left([C]_{22}^{\left(i-1^{\natural}\right)}+[C]_{11}^{(i)}+\Omega\left([J]_{22}^{(i-1)}+[J]_{11}^{(i)}\right)\right)
\end{array}\right]} \\
& {[\Psi]_{3}^{(i)}=-\Omega^{2}[M]_{12}^{(i-1)}+j \Omega\left([C]_{12}^{(i-1)}+\Omega[J]_{12}^{(i-1)}\right)+[K]_{12}^{(i-1)}}
\end{aligned}
$$

for $i=1, \ldots, N+1$, and $\left[u_{(0)}(j \Omega)\right]=0,[\Psi]_{1}^{(0)}=0,[M]_{22}^{(0)}=0,[K]_{22}^{(0)}=0,[J]_{22}^{(0)}=0,[M]_{11}^{(N+2)}=0$, $[K]_{11}^{(N+2)}=0,[J]_{11}^{(N+2)}=0,[\Psi]_{3}^{(N+2)}=0$ and $\left[u_{(N+2)}(j \Omega)\right]=0$.

Then, according to the structures of matrices $M, J, C$, and $K$, for the fundamental components whose frequency equals to the rotating speed, i.e., $\Omega=\omega$, Eq. (18) can be rewritten as

$$
\begin{aligned}
& \left\{\begin{array}{l}
{[\Psi]_{1}^{(i)}\left[u_{(i)}(j \Omega)\right]+[\Psi]_{2}^{(i+1)}\left[u_{(i+1)}(j \Omega)\right]+[\Psi]_{3}^{(i+2)}\left[u_{(i+2)}(j \Omega)\right]=0} \\
{[\Psi]_{1}^{(L-1)}\left[u_{(L-1)}(j \Omega)\right]+[\Psi]_{2}^{(L)}\left[u_{(L)}(j \Omega)\right]+[\Psi]_{3}^{(L+1)}\left[u_{(L+1)}(j \Omega)\right]=F_{c(L)}(j \Omega)} \\
{[\Psi]_{1}^{(L)}\left[u_{(L)}(j \Omega)\right]+[\Psi]_{2}^{(L+1)}\left[u_{(L+1)}(j \Omega)\right]+[\Psi]_{3}^{(L+2)}\left[u_{(L+2)}(j \Omega)\right]=F_{c(L+1)}(j \Omega)} \\
{[\Psi]_{1}^{(D-1)}\left[u_{(D-1)}(j \Omega)\right]+[\Psi]_{2}^{(D)}\left[u_{(D)}(j \Omega)\right]+[\Psi]_{3}^{(D+1)}\left[u_{(D+1)}(j \Omega)\right]=Q_{(D)}(j \Omega)}
\end{array}\right. \\
& (i=[0, \cdots, L-2] \cup[L+1, \cdots, D-2] \cup[D, \cdots, N])
\end{aligned}
$$


However, when applying the HBM method on the super-harmonic components whose frequency is an integral multiple of the rotating speed, i.e., $\Omega=n \omega,(n \geqslant 2)$, it can be known that, in this case, $Q_{(D)}(j \Omega)=0$, and so Eq. (18) can be rewritten as

$$
\left\{\begin{array}{c}
{[\Psi]_{1}^{(i)}\left[u_{(i)}(j \Omega)\right]+[\Psi]_{2}^{(i+1)}\left[u_{(i+1)}(j \Omega)\right]+[\Psi]_{3}^{(i+2)}\left[u_{(i+2)}(j \Omega)\right]=0} \\
{[\Psi]_{1}^{(L-1)}\left[u_{(L-1)}(j \Omega)\right]+[\Psi]_{2}^{(L)}\left[u_{(L)}(j \Omega)\right]+[\Psi]_{3}^{(L+1)}\left[u_{(L+1)}(j \Omega)\right]=F_{c(L)}(j \Omega)} \\
{[\Psi]_{1}^{(L)}\left[u_{(L)}(j \Omega)\right]+[\Psi]_{2}^{(L+1)}\left[u_{(L+1)}(j \Omega)\right]+[\Psi]_{3}^{(L+2)}\left[u_{(L+2)}(j \Omega)\right]=F_{c(L+1)}(j \Omega)} \\
(i=[0, \cdots, L-2] \cup[L+1, \cdots, N])
\end{array}\right.
$$

In addition, applying the HBM method on Eq. (17), then in the frequency domain, the relationship between the displacement vectors at two ends of the shaft element can be expressed as

$$
\left[u_{(i)}(j \Omega)\right]=\left[T^{(i, i+1)}(j \Omega)\right]\left[u_{(i+1)}(j \Omega)\right]
$$

where $\left[T^{(i, i+1)}(j \Omega)\right]$ defines the transmission matrix for the frequency component whose frequency is $\Omega$. Moreover, the differences between Eqs (19) and (20) imply that there exist differences between the transmission matrices which are associated with the fundamental components and which are associated with the super-harmonic components.

Denote the transmission matrix as $\left[T_{(1)}^{(i, i+1)}(j \Omega)\right]$ for the fundamental component case, and $\left[T_{(2)}^{(i, i+1)}(j \Omega)\right]$ for the super-harmonic component case. It can be deduced that $\left[T_{(1)}^{(i, i+1)}(j \Omega)\right]$ and $\left[T_{(2)}^{(i, i+1)}(j \Omega)\right]$ satisfy the relationship described by the following proposition.

Proposition: Assume $L<D$, then for $1 \leqslant i \leqslant L-1$ and $D \leqslant i \leqslant N,\left[T_{(1)}^{(i, i+1)}(j \Omega)\right]=\left[T_{(2)}^{(i, i+1)}(j \Omega)\right]$, and for $L \leqslant i \leqslant D-1,\left[T_{(1)}^{(i, i+1)}(j \Omega)\right] \neq\left[T_{(2)}^{(i, i+1)}(j \Omega)\right]$.

Before proving this proposition, it is worthy to note that as $\left[T_{(1)}^{(i, i+1)}(j \Omega)\right]$ is corresponding to the case where the frequency component $\Omega$ is fundamental component and, however, $\left[T_{(2)}^{(i, i+1)}(j \Omega)\right]$ is corresponding to the case where the frequency component $\Omega$ is super-harmonic component, then what the proposition describes actually are a comparison between two different scenarios. It is easy to create such two scenarios in practice, for example, by operating the machine at speed $\omega=\Omega$ and speed $\omega=\Omega / 2$ respectively.

\section{Proof of Proposition:}

From Eqs (19) and (20) it can be known that, when $i=0$, for both the fundamental and super-harmonic cases, $\left[u_{(1)}(j \Omega)\right]$ and $\left[u_{(2)}(j \Omega)\right]$ satisfy

$$
[\Psi]_{2}^{(1)}\left[u_{(1)}(j \Omega)\right]+[\Psi]_{3}^{(2)}\left[u_{(2)}(j \Omega)\right]=0
$$

From Eq. (22) $\left[T_{(1)}^{(i, i+1)}(j \Omega)\right]$ and $\left[T_{(2)}^{(i, i+1)}(j \Omega)\right]$ can be calculated as

$$
\left\{\begin{array}{l}
{\left[T_{(1)}^{(1,2)}(j \Omega)\right]=-\left([\Psi]_{2}^{(1)}\right)^{-1}\left([\Psi]_{3}^{(2)}\right)} \\
{\left[T_{(2)}^{(1,2)}(j \Omega)\right]=-\left([\Psi]_{2}^{(1)}\right)^{-1}\left([\Psi]_{3}^{(2)}\right)}
\end{array}\right.
$$

Obviously, $\left[T_{(1)}^{(1,2)}(j \Omega)\right]=\left[T_{(2)}^{(1,2)}(j \Omega)\right]$. Substituting Eq. (22) into Eqs (19) and (20) for $i=1$ gives

$$
\left\{\begin{array}{l}
{\left[T_{(1)}^{(2,3)}(j \Omega)\right]=-\left(\left([\Psi]_{1}^{(1)}\right)\left[T_{(1)}^{(1,2)}(j \Omega)\right]+[\Psi]_{2}^{(2)}\right)^{-1}\left([\Psi]_{3}^{(3)}\right)} \\
{\left[T_{(2)}^{(2,3)}(j \Omega)\right]=-\left(\left([\Psi]_{1}^{(1)}\right)\left[T_{(2)}^{(1,2)}(j \Omega)\right]+[\Psi]_{2}^{(2)}\right)^{-1}\left([\Psi]_{3}^{(3)}\right)}
\end{array}\right.
$$

Obviously, $\left[T_{(1)}^{(2,3)}(j \Omega)\right]=\left[T_{(2)}^{(2,3)}(j \Omega)\right]$. Iteratively applying the procedure to Eq. (19) and (20) until $i=L-1$, it can be proved that for $2 \leqslant i \leqslant L-1,\left[T_{(1)}^{(i, i+1)}(j \Omega)\right]=\left[T_{(2)}^{(i, i+1)}(j \Omega)\right]$ which can be calculated as 


$$
\left\{\begin{array}{l}
{\left[T_{(1)}^{(i, i+1)}(j \Omega)\right]=-\left(\left([\Psi]_{1}^{(i-1)}\right)\left[T_{(1)}^{(i-1, i)}(j \Omega)\right]+[\Psi]_{2}^{(i)}\right)^{-1}\left([\Psi]_{3}^{(i+1)}\right)} \\
{\left[T_{(2)}^{(i, i+1)}(j \Omega)\right]=-\left(\left([\Psi]_{1}^{(i-1)}\right)\left[T_{(2)}^{(i-1, i)}(j \Omega)\right]+[\Psi]_{2}^{(i)}\right)^{-1}\left([\Psi]_{3}^{(i+1)}\right)}
\end{array}\right.
$$

$$
(2 \leqslant i \leqslant L-1)
$$

Similarly, when $i=N$, for both the fundamental and super-harmonic cases, it can be known from Eqs (19) and (20) that $\left[u_{(N)}(j \Omega)\right]$ and $\left[u_{(N+1)}(j \Omega)\right]$ satisfy

$$
[\Psi]_{1}^{(N+1)}\left[u_{(N)}(j \Omega)\right]+[\Psi]_{2}^{(N+1)}\left[u_{(N+1)}(j \Omega)\right]=0
$$

From Eq. (26) it can be easily derived that $\left[T_{(1)}^{(N, N+1)}(j \Omega)\right]=\left[T_{(2)}^{(N, N+1)}(j \Omega)\right]$, and iteratively backwards conducting above procedure until $i=D$, it can be proved that for $D \leqslant i \leqslant N,\left[T_{(1)}^{(i, i+1)}(j \Omega)\right]=\left[T_{(2)}^{(i, i+1)}(j \Omega)\right]$.

For $\left[u_{(D-1)}(j \Omega)\right],\left[u_{(D)}(j \Omega)\right],\left[u_{(D+1)}(j \Omega)\right]$, in the case where the frequency component $\Omega$ is a fundamental frequency component, the following relationship is tenable

$$
[\Psi]_{1}^{(D-1)}\left[u_{(D-1)}(j \Omega)\right]+[\Psi]_{2}^{(D)}\left[u_{(D)}(j \Omega)\right]+[\Psi]_{3}^{(D+1)}\left[u_{(D+1)}(j \Omega)\right]=Q_{(D)}(j \Omega)
$$

On the contrary, if the frequency component $\Omega$ is a super-harmonic component, then

$$
[\Psi]_{1}^{(D-1)}\left[u_{(D-1)}(j \Omega)\right]+[\Psi]_{2}^{(D)}\left[u_{(D)}(j \Omega)\right]+[\Psi]_{3}^{(D+1)}\left[u_{(D+1)}(j \Omega)\right]=0
$$

From Eq. (28), $\left[T_{(2)}^{(D-1, D)}(j \Omega)\right]$ can be determined as

$$
\left[T_{(2)}^{(D-1, D)}(j \Omega)\right]=-\left([\Psi]_{1}^{(D-1)}\right)^{-1}\left([\Psi]_{2}^{(D)}+[\Psi]_{3}^{(D+1)}\left[T_{(2)}^{(D, D+1)}(j \Omega)\right]^{-1}\right)
$$

However, Eq. (27) shows that in the fundamental frequency component case the following relationship holds on $\left[u_{(D-1)}(j \Omega)\right]$ and $\left[u_{(D)}(j \Omega)\right]$,

$$
\left[u_{(D-1)}(j \Omega)\right]=\left[T_{(2)}^{(D-1, D)}(j \Omega)\right]\left[u_{(D)}(j \Omega)\right]+\left([\Psi]_{1}^{(D-1)}\right)^{-1} Q_{(D)}(j \Omega)
$$

As $Q_{(D)}(j \Omega) \neq 0$, so in the fundamental frequency component case, $\left[u_{(D-1)}(j \Omega)\right] \neq\left[T_{(2)}^{(D-1, D)}(j \Omega)\right]\left[u_{(D)}(j \Omega)\right]$. This means

$$
\left[T_{(1)}^{(D-1, D)}(j \Omega)\right] \neq\left[T_{(2)}^{(D-1, D)}(j \Omega)\right]
$$

Consequently, substituting Eq. (31) into the following equation

$$
[\Psi]_{1}^{(D-2)}\left[u_{(D-2)}(j \Omega)\right]+[\Psi]_{2}^{(D-1)}\left[u_{(D-1)}(j \Omega)\right]+[\Psi]_{3}^{(D)}\left[u_{(D)}(j \Omega)\right]=0
$$

which determine the relationships between $\left[u_{(D-2)}(j \Omega)\right],\left[u_{(D-1)}(j \Omega)\right],\left[u_{(D)}(j \Omega)\right]$ for both the fundamental and super-harmonic component cases, yields

$$
\left\{\begin{array}{l}
{\left[T_{(1)}^{(D-2, D-1)}(j \Omega)\right]=-\left([\Psi]_{1}^{(D-2)}\right)^{-1}\left([\Psi]_{2}^{(D-1)}+[\Psi]_{3}^{(D)}\left[T_{(1)}^{(D-1, D)}(j \Omega)\right]^{-1}\right)} \\
{\left[T_{(2)}^{\left(D-2, D-1^{4}\right)}(j \Omega)\right]=-\left([\Psi]_{1}^{(D-2)}\right)^{-1}\left([\Psi]_{2}^{(D-1)}+[\Psi]_{3}^{(D)}\left[T_{(2)}^{(D-1, D)}(j \Omega)\right]^{-1}\right)}
\end{array}\right.
$$

As $\left[T_{(1)}^{(D-1, D)}(j \Omega)\right] \neq\left[T_{(2)}^{(D-1, D)}(j \Omega)\right]$, it is obvious that $\left[T_{(1)}^{(D-2, D-1)}(j \Omega)\right] \neq\left[T_{(2)}^{(D-2, D-1)}(j \Omega)\right]$. Iteratively backwards conducting above procedure until $i=L$, it can be proved that for $L \leqslant i \leqslant D-1,\left[T_{(1)}^{(i, i+1)}(j \Omega)\right] \neq$ $\left[T_{(2)}^{(i, i+1)}(j \Omega)\right]$. Thus the proposition is proved.

Actually, the above procedure of proving the proposition provides a straightforward way to calculate the values of $\left[T_{(1)}^{(i, i+1)}(j \Omega)\right]$ for $i=[1, \cdots, L-1] \cup[D, \cdots, N]$ and $\left[T_{(2)}^{(i, i+1)}(j \Omega)\right]$ for $i=[1, \cdots, L-1] \cup[L+1, \cdots, N]$. Further denote $\left[T_{(1)}^{(0,1)}(j \Omega)\right]=0,\left[T_{(2)}^{(0,1)}(j \Omega)\right]=0$ and $\left[T_{(1)}^{(N+1, N+2)}(j \Omega)\right]=0$ and $\left[T_{(2)}^{(N+1, N+2)}(j \Omega)\right]=0$, the way can be summarized as follows 


$$
\begin{array}{ll}
{\left[T_{(1)}^{(i, i+1)}(j \Omega)\right]=-\left(\left([\Psi]_{1}^{(i-1)}\right)\left[T_{(1)}^{(i-1, i)}(j \Omega)\right]+[\Psi]_{2}^{(i)}\right)^{-1}\left([\Psi]_{3}^{(i+1)}\right)} & (1 \leqslant i \leqslant L-1) \\
{\left[T_{(1)}^{(i, i+1)}(j \Omega)\right]=-\left([\Psi]_{1}^{(i)}\right)^{-1}\left([\Psi]_{2}^{(i+1)}+[\Psi]_{3}^{(i+2)}\left[T_{(1)}^{(i+1, i+2)}(j \Omega)\right]^{-1}\right)} & (D \leqslant i \leqslant N) \\
{\left[T_{(2)}^{(i, i+1)}(j \Omega)\right]=-\left(\left([\Psi]_{1}^{(i-1)}\right)\left[T_{(2)}^{(i-1, i)}(j \Omega)\right]+[\Psi]_{2}^{(i)}\right)^{-1}\left([\Psi]_{3}^{(i+1)}\right)} & (1 \leqslant i \leqslant L-1) \\
{\left[T_{(2)}^{(i, i+1)}(j \Omega)\right]=-\left([\Psi]_{1}^{(i)}\right)^{-1}\left([\Psi]_{2}^{(i+1)}+[\Psi]_{3}^{(i+2)}\left[T_{(2)}^{(i+1, i+2)}(j \Omega)\right]^{-1}\right)} & (L+1 \leqslant i \leqslant N)
\end{array}
$$

The proposition along with Eqs (34) (37) reveals how the presence of crack may affect the transmission matrices of a rotor system. While the four equations provide a straightforward way to calculate the theoretical values for part of the transmission matrices and reveal there exist differences between the transmission matrices for the fundamental frequency and for the other super-harmonic frequencies, and the proposition further reveals that the differences are mainly determined by the crack position in the rotor. The appearance of super-harmonic frequency components have long been recognized as a sensitive indicator to the presence of crack in rotor systems, and these new discovered important results about the effects of crack (especially the crack location) on the transmission matrices could provide novel methods to detect the exact position of crack in a rotor.

It is worthy to note here that, as indicated by Eqs $(34) \sim(37)$ the values of $\left[T_{(1)}^{(i, i+1)}(j \Omega)\right](1 \leqslant i \leqslant L-1$ and $D \leqslant i \leqslant N)$ and $\left[T_{(2)}^{(i, i+1)}(j \Omega)\right](1 \leqslant i \leqslant L-1$ and $L+1 \leqslant i \leqslant N)$ are only determined by the linear property characteristic parameters of the rotor system and are irrelevant to the crack characteristic parameters, such as the crack depth. On the contrary, the values of $\left[T_{(1)}^{(i, i+1)}(j \Omega)\right](L \leqslant i \leqslant D-1)$ and $\left[T_{(2)}^{(i, i+1)}(j \Omega)\right](i=L)$ are dependent on both the linear property characteristic parameters and the crack characteristic parameters, and there is no a straightforward way like Eq (36) (39) to calculate them.

As indicated by Eq. (18), the effects of crack on rotor systems are represented by the term $F_{c}(j \Omega)$ whose specific form actually is not provided. Moreover, it is not required to know the specific form of $F_{c}(j \Omega)$ when carrying out above deduction to obtain Eqs (28) and (29) and proving the proposition. This means that the conclusions reached in this section can not only apply to the crack case but also can apply to other fault cases, which should have a common feature, that is, the their appearances could introduce some extra frequency components, besides the fundamental frequency component, to the system response of the rotor systems being subjected to the imbalance force. A best known example is the rubbing-impact fault [30].

\section{Numerical validation}

In order to validate the analysis results obtained in Section 3, a numerical experiment is designed in this section to be conducted on a rotor system shown in Fig. 1. The rotor is discretized into 10 Timoshenko beam elements, among which the third element is with crack. All the values of the parameters are given in Table 1.

The numerical experiment is design to validate that the fundamental and super-harmonic frequency components of the system responses of the crack rotor system satisfy the relationships, i.e., for $1 \leqslant i \leqslant L-1$ and $D \leqslant i \leqslant N$

$$
\left[u_{(i)}(j \omega)\right]=\left[T_{(1)}^{(i, i+1)}(j \omega)\right]\left[u_{(i+1)}(j \omega)\right]
$$

and for $1 \leqslant i \leqslant L-1$ and $D \leqslant i \leqslant N$,

$$
\left[u_{(i)}(j n \omega)\right]=\left[T_{(2)}^{(i, i+1)}(j n \omega)\right]\left[u_{(i+1)}(j n \omega)\right](n \geqslant 2)
$$


Table 1

Details of the rotor parameters

\begin{tabular}{ll}
\hline Parameters & Physical dimension \\
\hline Length of the shaft & $0.5 \mathrm{~m}$ \\
Diameter of the shaft $r$ & $20 \mathrm{~mm}$ \\
Crack depth $a$ & $10 \mathrm{~mm}$ \\
Young's modulus of elasticity $E$ & $2.08 \times 10^{11} \mathrm{~N} / \mathrm{m}^{2}$ \\
the Possion's ratio $v$ & 0.3 \\
Density of the shaft $\rho$ & $7780 \mathrm{Kg} / \mathrm{m}^{3}$ \\
Mass of the disk $m$ & $5.5 \mathrm{Kg}$ \\
the moment of inertia of the disk $I_{p}$ & $0.01546 \mathrm{Kg} . \mathrm{m}^{2}$ \\
Eccentricity of imbalance mass $(m e)$ & $0.4 \times 10^{-3} \mathrm{Kg} . \mathrm{m}$ \\
Stiffness of Bearing $K_{b x}, K_{b y}$ & $1.0 \times 10^{5} \mathrm{~N} / \mathrm{m}$ \\
Damping of Bearing & $2.0 \times 10^{3} \mathrm{~N} . \mathrm{s} / \mathrm{m}$ \\
\hline
\end{tabular}

Table 2

\begin{tabular}{rrrrr}
\multicolumn{5}{c}{ The values of $\left[T_{(1)}^{(i, i+1)}(j \omega)\right](\omega=10 \mathrm{~Hz})$} \\
\hline$i$ & \multicolumn{4}{c}{$\left[T_{(1)}^{(i, i+1)}(j \omega)\right]$} \\
\hline 1 & $1.0008-0.0002 \mathrm{i}$ & $-0.0000-0.0000 \mathrm{i}$ & $-0.0500+0.0000 \mathrm{i}$ & $0.0000+0.0000 \mathrm{i}$ \\
& $0.0000+0.0000 \mathrm{i}$ & $1.0004-0.0002 \mathrm{i}$ & $-0.0000-0.0000 \mathrm{i}$ & $-0.0500+0.0000 \mathrm{i}$ \\
& $-0.0197+0.0060 \mathrm{i}$ & $0.0000+0.0000 \mathrm{i}$ & $1.0008-0.0003 \mathrm{i}$ & $-0.0000-0.0003 \mathrm{i}$ \\
& $-0.0000-0.0000 \mathrm{i}$ & $-0.0101+0.0060 \mathrm{i}$ & $0.0000+0.0003 \mathrm{i}$ & $1.0003-0.0003 \mathrm{i}$ \\
2 & $1.0048-0.0005 \mathrm{i}$ & $-0.0000-0.0000 \mathrm{i}$ & $-0.0503+0.0001 \mathrm{i}$ & $0.0000+0.0000 \mathrm{i}$ \\
& $0.0000+0.0000 \mathrm{i}$ & $1.0040-0.0005 \mathrm{i}$ & $-0.0000-0.0000 \mathrm{i}$ & $-0.0503+0.0001 \mathrm{i}$ \\
& $-0.1584+0.0184 \mathrm{i}$ & $0.0000+0.0001 \mathrm{i}$ & $1.0117-0.0018 \mathrm{i}$ & $-0.0000-0.0009 \mathrm{i}$ \\
& $-0.0000-0.0001 \mathrm{i}$ & $-0.1291+0.0183 \mathrm{i}$ & $0.0000+0.0009 \mathrm{i}$ & $1.0087-0.0018 \mathrm{i}$ \\
6 & $1.0383-0.0020 \mathrm{i}$ & $-0.0000-0.0001 \mathrm{i}$ & $-0.0451-0.0004 \mathrm{i}$ & $-0.0000-0.0001 \mathrm{i}$ \\
& $0.0000+0.0001 \mathrm{i}$ & $1.0352-0.0019 \mathrm{i}$ & $0.0000+0.0001 \mathrm{i}$ & $-0.0457-0.0004 \mathrm{i}$ \\
& $-1.6489+0.0819 \mathrm{i}$ & $0.0003+0.0033 \mathrm{i}$ & $0.7930+0.0155 \mathrm{i}$ & $0.0001+0.0036 \mathrm{i}$ \\
& $-0.0003-0.0036 \mathrm{i}$ & $-1.5216+0.0782 \mathrm{i}$ & $-0.0001-0.0036 \mathrm{i}$ & $0.8170+0.0147 \mathrm{i}$ \\
8 & $1.0096-0.0007 \mathrm{i}$ & $-0.0000-0.0000 \mathrm{i}$ & $-0.0494-0.0001 \mathrm{i}$ & $-0.0000-0.0000 \mathrm{i}$ \\
& $0.0000+0.0000 \mathrm{i}$ & $1.0085-0.0007 \mathrm{i}$ & $0.0000+0.0000 \mathrm{i}$ & $-0.0495-0.0001 \mathrm{i}$ \\
& $-0.4440+0.0308 \mathrm{i}$ & $0.0000+0.0001 \mathrm{i}$ & $0.9748+0.0031 \mathrm{i}$ & $0.0000+0.0015 \mathrm{i}$ \\
& $-0.0000-0.0001 \mathrm{i}$ & $-0.3952+0.0306 \mathrm{i}$ & $-0.0000-0.0015 \mathrm{i}$ & $0.9797+0.0031 \mathrm{i}$ \\
10 & $1.0002-0.0001 \mathrm{i}$ & $0.0000-0.0000 \mathrm{i}$ & $-0.0500-0.0000 \mathrm{i}$ & $0.0000-0.0000 \mathrm{i}$ \\
& $-0.0000-0.0000 \mathrm{i}$ & $1.0001-0.0001 \mathrm{i}$ & $-0.0000+0.0000 \mathrm{i}$ & $-0.0500-0.0000 \mathrm{i}$ \\
& $-0.0197+0.0060 \mathrm{i}$ & $-0.0000+0.0000 \mathrm{i}$ & $1.0002-0.0000 \mathrm{i}$ & $0.0000+0.0003 \mathrm{i}$ \\
& $0.0000+0.0000 \mathrm{i}$ & $-0.0101+0.0060 \mathrm{i}$ & $0.0000-0.0003 \mathrm{i}$ & $1.0002-0.0000 \mathrm{i}$ \\
\hline
\end{tabular}

in which $\left[T_{(1)}^{(i, i+1)}(j \Omega)\right]$ and $\left[T_{(2)}^{(i, i+1)}(j \Omega)\right]$ are calculated by Eq. $(34) \sim(37)$. Here, $\omega$ is the rotating speed and is taken as $10 \mathrm{~Hz}$ in this case study. The system responses of the cracked rotor system operating with rotating speed $\omega=10 \mathrm{~Hz}$ are obtained by using the fourth-order Runge-Kutta method. From the steady-state simulation system responses, the fundamental and the second super-harmonics are extracted. As the crack is in the third element, so $L=3$, and as the disk with imbalance is at the sixth node, therefore $D=6$. Therefore, in this case study, for $1 \leqslant i \leqslant 2$ and $6 \leqslant i \leqslant 10,\left[T_{(1)}^{(i, i+1)}(j \omega)\right]$ can be calculated using Eqs (34) and (35), and part of the calculated results are given in Table 2. Moreover, the relationship should be tenable for the fundamental components extracted from the simulation responses, i.e., $\left[u_{(i)}(j \omega)\right]=\left[T_{(1)}^{(i, i+1)}(j \omega)\right]\left[u_{(i+1)}(j \omega)\right](1 \leqslant i \leqslant 2$ and $6 \leqslant i \leqslant 10)$. Obviously, the results (only for $i=1,2,6,8,10$ ) shown in Table 3 indicate that the simulation results exactly follow this relationship.

In addition, according to the conclusions obtained in Section 3 , the values of $\left[T_{(2)}^{(i, i+1)}(j 2 \omega)\right]$ could be calculated using Eqs (36) and (37) for $1 \leqslant i \leqslant 2$ and $4 \leqslant i \leqslant 10$, and part of the results are given Table 4. Moreover, the second super-harmonics of simulation responses should satisfy the relationship, i.e., $\left[u_{(i)}(j 2 \omega)\right]=\left[T_{(2)}^{(i, i+1)}(j 2 \omega)\right]\left[u_{(i+1)}(j 2 \omega)\right]$ for $(1 \leqslant i \leqslant 2$ and $4 \leqslant i \leqslant 10)$. It can be seen from the results given in Table 5 that the second super-harmonic components of the simulation results exactly follow this relationship although there are small deviations because of the numerical error. 
Table 3

Validation of relationship Eq. (38)

\begin{tabular}{|c|c|c|c|c|c|}
\hline \multicolumn{2}{|c|}{$u_{(i+1)}(j \omega)\left(\times 10^{-5}\right)$} & \multicolumn{2}{|c|}{$\begin{aligned} {\left[T_{(1)}^{(i, i+1)}\right.} & (j \omega)]\left[u_{(i+1)}(j \omega)\right] \\
& \left(\times 10^{-5}\right)\end{aligned}$} & \multicolumn{2}{|c|}{$u_{(i)}(j \omega)\left(\times 10^{-5}\right)$} \\
\hline \multicolumn{2}{|c|}{$-0.0698-0.0008 \mathrm{i}$} & \multicolumn{2}{|c|}{$-0.0797-0.0004 \mathrm{i}$} & \multicolumn{2}{|c|}{$-0.0797-0.0004 \mathrm{i}$} \\
\hline \multicolumn{2}{|c|}{$-0.0008+0.0698 \mathrm{i}$} & \multicolumn{2}{|c|}{$-0.0004+0.0796 \mathrm{i}$} & \multicolumn{2}{|c|}{$-0.0004+0.0796 \mathrm{i}$} \\
\hline \multicolumn{2}{|c|}{$0.1959-0.0088 \mathrm{i}$} & \multicolumn{2}{|c|}{$0.1973-0.0092 \mathrm{i}$} & \multicolumn{2}{|c|}{$0.1973-0.0092 \mathrm{i}$} \\
\hline \multicolumn{2}{|c|}{$-0.0088-0.1956 \mathrm{i}$} & \multicolumn{2}{|c|}{$-0.0092-0.1964 \mathrm{i}$} & \multicolumn{2}{|c|}{$-0.0092-0.1971 \mathrm{i}$} \\
\hline \multicolumn{2}{|c|}{$-0.0602-0.0012 \mathrm{i}$} & \multicolumn{2}{|c|}{$-0.0698-0.0008 \mathrm{i}$} & \multicolumn{2}{|c|}{$-0.0698-0.0008 \mathrm{i}$} \\
\hline \multicolumn{2}{|c|}{$-0.0012+0.0602 \mathrm{i}$} & \multicolumn{2}{|c|}{$-0.0008+0.0697 i$} & \multicolumn{2}{|c|}{$-0.0008+0.0698 \mathrm{i}$} \\
\hline \multicolumn{2}{|c|}{$0.1843-0.0074 \mathrm{i}$} & 0.1959 & $-0.0088 \mathrm{i}$ & & $1959-0.0088 \mathrm{i}$ \\
\hline$-0.0074-0.18$ & & -0.0088 & $-0.1933 \mathrm{i}$ & & $0088-0.1956 \mathrm{i}$ \\
\hline$-0.0454-0.00$ & & -0.0429 & $-0.0018 \mathrm{i}$ & & $0429-0.0018 \mathrm{i}$ \\
\hline$-0.0018+0.04$ & & -0.0018 & $+0.0427 \mathrm{i}$ & & $0018+0.0429 \mathrm{i}$ \\
\hline$-0.0940+0.00$ & & -0.0000 & $+0.0000 \mathrm{i}$ & & $0001+0.0000 \mathrm{i}$ \\
\hline $0.0028+0.09$ & & 0.0001 & $+0.0081 \mathrm{i}$ & & $0001+0.0000 \mathrm{i}$ \\
\hline$-0.0602-0.00$ & & -0.0517 & $-0.0016 \mathrm{i}$ & & $0517-0.0016 \mathrm{i}$ \\
\hline$-0.0012+0.06$ & & -0.0016 & $+0.0516 \mathrm{i}$ & & $0016+0.0517 \mathrm{i}$ \\
\hline$-0.1840+0.00$ & & -0.1529 & $+0.0054 \mathrm{i}$ & & $1529+0.0054 \mathrm{i}$ \\
\hline $0.0074+0.18$ & & 0.0054 & $+0.1567 \mathrm{i}$ & & $0054+0.1529 \mathrm{i}$ \\
\hline$-0.0796-0.00$ & & -0.0698 & $-0.0008 \mathrm{i}$ & & $0698-0.0008 \mathrm{i}$ \\
\hline$-0.0004+0.07$ & & -0.0008 & $+0.0698 \mathrm{i}$ & & $0008+0.0698 \mathrm{i}$ \\
\hline$-0.1971+0.00$ & & -0.1956 & $+0.0088 \mathrm{i}$ & & $1956+0.0088 \mathrm{i}$ \\
\hline $0.0092+0.19$ & & 0.0088 & $+0.1962 \mathrm{i}$ & & $088+0.1955 \mathrm{i}$ \\
\hline & & Table 4 & & & \\
\hline & valu & f $\left[T_{(2)}^{(i, i+1)}(j\right.$ & ט)] $(\omega=10$ & & \\
\hline & & {$\left[T_{(2)}^{(i, i+}\right.$} & $2 \omega)]$ & & \\
\hline $1.0035-0.0004 \mathrm{i}$ & -0 . & $.0000-0.0000 \mathrm{i}$ & $-0.0501+0$. & & $0.0000+0.0000 \mathrm{i}$ \\
\hline $0.0000+0.0000 \mathrm{i}$ & & $032-0.0004 \mathrm{i}$ & $-0.0000-0$ & & $-0.0501+0.0000 \mathrm{i}$ \\
\hline$-0.0934+0.0121 \mathrm{i}$ & & $.0000+0.0001 \mathrm{i}$ & $1.0040-0$. & & $-0.0000-0.0012 \mathrm{i}$ \\
\hline$-0.0000-0.0001 \mathrm{i}$ & -0 . & $.0838+0.0121 \mathrm{i}$ & $0.0000+0$. & & $1.0036-0.0006 \mathrm{i}$ \\
\hline $0.9215-0.0040 \mathrm{i}$ & & $.0002-0.0034 \mathrm{i}$ & $-0.0747-0$. & & $0.0000-0.0004 \mathrm{i}$ \\
\hline$-0.0002+0.0035 \mathrm{i}$ & & $9183-0.0042 \mathrm{i}$ & $-0.0000+0$. & & $-0.0751-0.0006 \mathrm{i}$ \\
\hline $3.0235+0.1665 \mathrm{i}$ & -0 . & $.0072+0.1478 \mathrm{i}$ & $2.0143+0$. & & $-0.0009+0.0191 \mathrm{i}$ \\
\hline $0.0072-0.1489 \mathrm{i}$ & & $1597+0.1770 \mathrm{i}$ & $0.0009-0.0$ & & $2.0349+0.0268 \mathrm{i}$ \\
\hline $1.3132-0.0245 \mathrm{i}$ & -0 . & $.0013-0.0083 \mathrm{i}$ & $-0.0068-0.0$ & & $-0.0003-0.0019 \mathrm{i}$ \\
\hline $0.0013+0.0084 \mathrm{i}$ & & $2948-0.0222 \mathrm{i}$ & $0.0002+0.0$ & & $-0.0098-0.0036 \mathrm{i}$ \\
\hline$-13.3286+1.0258 \mathrm{i}$ & & $.0548+0.3395 \mathrm{i}$ & $-0.8187+0.1$ & $57 \mathrm{i}$ & $0.0104+0.0791 \mathrm{i}$ \\
\hline$-0.0555-0.3452 \mathrm{i}$ & -12 & $.5588+0.9294 \mathrm{i}$ & $-0.0104-0.0$ & & $-0.6937+0.1510 \mathrm{i}$ \\
\hline $1.0411-0.0016 \mathrm{i}$ & -0 . & $.0000-0.0001 \mathrm{i}$ & $-0.0475-0.0$ & & $-0.0000-0.0001 \mathrm{i}$ \\
\hline $0.0000+0.0001 \mathrm{i}$ & & $.0398-0.0015 \mathrm{i}$ & $0.0000+0.0$ & & $-0.0476-0.0002 \mathrm{i}$ \\
\hline$-1.8910+0.0668 \mathrm{i}$ & & $.0002+0.0023 \mathrm{i}$ & $0.8889+0.0$ & & $0.0000+0.0063 \mathrm{i}$ \\
\hline$-0.0002-0.0024 \mathrm{i}$ & -1 . & $8381+0.0664 \mathrm{i}$ & $-0.0000-0.0$ & & $0.8941+0.0065 \mathrm{i}$ \\
\hline $1.0011-0.0002 \mathrm{i}$ & & $.0000+0.0000 \mathrm{i}$ & $-0.0500+0.0$ & $0 \mathrm{i}$ & $-0.0000-0.0000 \mathrm{i}$ \\
\hline$-0.0000-0.0000 \mathrm{i}$ & & $.0010-0.0002 \mathrm{i}$ & $-0.0000+0.0$ & & $-0.0500+0.0000 \mathrm{i}$ \\
\hline$-0.0931+0.0120 \mathrm{i}$ & -0 . & $.0000-0.0000 \mathrm{i}$ & $1.0006+0.0$ & & $0.0000+0.0012 \mathrm{i}$ \\
\hline $0.0000+0.0000 \mathrm{i}$ & -0 . & $.0836+0.0120 \mathrm{i}$ & $0.0000-0.0$ & & $1.0006+0.0000 \mathrm{i}$ \\
\hline
\end{tabular}

The results given in Table 6 are devoted to validating the relationship $\left[T_{(1)}^{(i, i+1)}(j \Omega)\right] \neq\left[T_{(2)}^{(i, i+1)}(j \Omega)\right]$ for $L \leqslant i \leqslant$ $D-1$, that is,

$$
\left[u_{(i)}(j \omega)\right] \neq\left[T_{(2)}^{(i, i+1)}(j \omega)\right]\left[u_{(i+1)}(j \omega)\right] \quad(3 \leqslant i \leqslant 5)
$$

for this case study. Moreover, because there is not a method available to calculate the theoretical values of $\left[T_{(2)}^{(3,4)}(j \omega)\right]$, then Table 6 only gives comparisons between $\left[u_{(i)}(j \omega)\right]$ and $\left[T_{(2)}^{(i, i+1)}(j \omega)\right]\left[u_{(i+1)}(j \omega)\right]$ for $i=4$ and 5. The rotating speed is $\omega=20 \mathrm{~Hz}$. Obviously, the results validate this relationship. 
Table 5

Validation of relationship Eq. (39)

\begin{tabular}{rrcr}
\hline$i$ & $u_{(i+1)}(j 2 \omega)$ & {$\left[T_{(2)}^{(i, i+1)}(j \omega)\right]\left[u_{(i+1)}(j 2 \omega)\right]$} & \multicolumn{1}{c}{$\begin{array}{c}u_{(i)}(j 2 \omega) \\
\left(\times 10^{-8}\right)\end{array}$} \\
\hline 1 & \multicolumn{1}{c}{$\left(\times 10^{-8}\right)$} & \multicolumn{1}{c}{$\left(\times 10^{-8}\right)$} & $0.0282+0.0031 \mathrm{i}$ \\
& $0.0128+0.0013 \mathrm{i}$ & $0.0282+0.0031 \mathrm{i}$ & $-0.0028+0.0448 \mathrm{i}$ \\
& $-0.0012+0.0245 \mathrm{i}$ & $-0.0028+0.0448 \mathrm{i}$ & $-0.3072-0.0363 \mathrm{i}$ \\
& $-0.3050-0.0356 \mathrm{i}$ & $-0.3069-0.0362 \mathrm{i}$ & $0.0326-0.4079 \mathrm{i}$ \\
4 & $0.0319-0.4049 \mathrm{i}$ & $0.0326-0.4080 \mathrm{i}$ & $-0.0403-0.0317 \mathrm{i}$ \\
& $-0.0112-0.0343 \mathrm{i}$ & $-0.0421-0.0300 \mathrm{i}$ & $0.0053+0.0078 \mathrm{i}$ \\
& $0.0036-0.0019 \mathrm{i}$ & $0.0058+0.0082 \mathrm{i}$ & $-0.1087+0.8101 \mathrm{i}$ \\
& $0.0158+0.4037 \mathrm{i}$ & $-0.1104+0.8061 \mathrm{i}$ & $-0.0518-0.2758 \mathrm{i}$ \\
& $-0.0369-0.1341 \mathrm{i}$ & $-0.0524-0.2725 \mathrm{i}$ & $-0.0102-0.0190 \mathrm{i}$ \\
6 & $-0.0076-00.014 \mathrm{i}$ & $-0.0107-0.0186 \mathrm{i}$ & $0.0023-0.0058 \mathrm{i}$ \\
& $0.0013-0.0040 \mathrm{i}$ & $0.0021-0.0060 \mathrm{i}$ & $0.0441+0.1819 \mathrm{i}$ \\
& $0.0786+0.0110 \mathrm{i}$ & $0.0438+0.1833 \mathrm{i}$ & $-0.0228-0.0139 \mathrm{i}$ \\
& $-0.0090+0.0891 \mathrm{i}$ & $-0.0242-0.0146 \mathrm{i}$ & $-0.0029-0.0007 \mathrm{i}$ \\
8 & $0.0031+0.0002 \mathrm{i}$ & $-0.0029-0.0007 \mathrm{i}$ & $0.0007+0.0026 \mathrm{i}$ \\
& $-0.0002+0.0111 \mathrm{i}$ & $0.0007+0.0028 \mathrm{i}$ & $0.1091+0.0167 \mathrm{i}$ \\
& $0.1286+0.0206 \mathrm{i}$ & $0.1098+0.0170 \mathrm{i}$ & $-0.0159+0.1560 \mathrm{i}$ \\
& $-0.0197+0.1846 \mathrm{i}$ & $-0.0154+0.1456 \mathrm{i}$ & $0.0098+0.0013 \mathrm{i}$ \\
10 & $0.0167+0.0025 \mathrm{i}$ & $0.0098+0.0013 \mathrm{i}$ & $-0.0013+0.0207 \mathrm{i}$ \\
& $-0.0023+0.0307 \mathrm{i}$ & $-0.0013+0.0207 \mathrm{i}$ & $0.1372+0.0226 \mathrm{i}$ \\
& $0.1385+0.0230 \mathrm{i}$ & $0.1373+0.0226 \mathrm{i}$ & $-0.0216+0.1970 \mathrm{i}$ \\
\hline & $-0.0221+0.1989 \mathrm{i}$ & $-0.0215+0.1966 \mathrm{i}$ &
\end{tabular}

Table 6

Validation of relationship Eq. (40)

\begin{tabular}{rccr}
\hline$i$ & $\begin{array}{c}u_{(i+1)}(j \omega) \\
\left(\times 10^{-5}\right)\end{array}$ & {$\left[T_{(2)}^{(i, i+1)}(j \omega)\right]\left[u_{(i+1)}(j \omega)\right]$} & \multicolumn{1}{c}{$u_{(i)}(j \omega)$} \\
& \multicolumn{1}{c}{$\left(\times 10^{-5}\right)$} & \multicolumn{1}{c}{$\left(\times 10^{-5}\right)$} \\
\hline 4 & $0.0402-0.0075 \mathrm{i}$ & $-0.0163-0.0053 \mathrm{i}$ & $-0.0082-0.0053 \mathrm{i}$ \\
& $0.7024-0.0354 \mathrm{i}$ & $1.5580-0.0701 \mathrm{i}$ & $1.2112-0.0661 \mathrm{i}$ \\
& $-0.0075-0.0401 \mathrm{i}$ & $-0.0053+0.0163 \mathrm{i}$ & $-0.0053+0.0093 \mathrm{i}$ \\
& $-0.0354-0.7023 \mathrm{i}$ & $-0.0711-1.5782 \mathrm{i}$ & $-0.0661-1.2101 \mathrm{i}$ \\
5 & $0.0585-0.0084 \mathrm{i}$ & $0.0373-0.0075 \mathrm{i}$ & $0.0402-0.0075 \mathrm{i}$ \\
& $-0.0007+0.0000 \mathrm{i}$ & $0.8721-0.0349 \mathrm{i}$ & $0.7024-0.0354 \mathrm{i}$ \\
& $-0.0084-0.0584 \mathrm{i}$ & $-0.0076-0.0356 \mathrm{i}$ & $-0.0075-0.0401 \mathrm{i}$ \\
& $0.0001+0.0004 \mathrm{i}$ & $-0.0302-0.9409 \mathrm{i}$ & $-0.0354-0.7023 \mathrm{i}$ \\
\hline
\end{tabular}

Therefore, the numerical studies verify the conclusions and properties of the transmission matrices of the cracked rotor system as described in Section 3.

\section{Conclusions}

In the present study, the influence of crack on the transmission matrices of the rotor systems is investigated by using the FEM analysis and the HBM technique. It is for the first time revealed that there are differences between the transmission matrices for the fundamental frequency components and the transmission matrices for the superharmonic components, and the differences are mainly determined by the crack location. The results are validated by numerical experiments. The results obtained in this study are of significance for the development of effective crack detection methods in practice.

\section{Acknowledgements}

The authors gratefully acknowledge the supports of the Natural Science Foundation of China (No. 10902068 and No. 10732060), the NCET in University of China (No. NCET-10-0548) and the EPSRC, UK, for this work. 


\section{References}

[1] A.D. Dimarogonas, Vibration of cracked structures: A state of the art review, Engineering Fracture Mechanics 55 (1996), $831-857$.

[2] R. Gasch, A survey of the dynamic behaviour of a simple rotating shaft with a transverse crack, Journal of Sound and Vibration 160 (1993), 313-332.

[3] J. Wauer, On the dynamics of cracked rotors: A literature survey, Applied Mechanics Reviews 43 (1990), 13-17.

[4] S Chinchalkar, Determination of crack location in beams using natural frequencies, Journal of Sound and Vibration 247 (2001), $417-429$.

[5] P.N. Saavedra and L.A. Cuitino, Vibration analysis of rotor for crack identification, Journal of Vibration and Control 8 (2002), $51-67$.

[6] L. Lazzeri, S. Cecconi, M. Faravelli et al., Second Harmonic Vibration Monitoring of a Cracked Shaft in a Turbo-Generator, in Proceedings of the American Power Conference Chicago, IL, 54 (1992), 1337-1342.

[7] D.E. Bently, A. Muszynska, Detection of Rotor Cracks, in Proceedings of Texas A\&M University 15th Turbomachinery Symposium and Short Courses, Corpus Christi, TX, (November 1986), 129-139.

[8] S.A. Adewusi and B.O. Al-Bedoor, Wavelet Analysis of Vibration Signals of AN Overhang Rotor with a Propagating Transverse Crack, Journal of Sound and Vibration 246 (2001), 777-793.

[9] J. Zou and J. Chen, A comparative study on time-frequency feature of cracked rotor by Wigner-Ville distribution and wavelet transform, Journal of Sound and Vibration 276 (2004), 1-11.

[10] T.R. Babu, S. Srikanth and A.S. Sekhar, Hilbert-Huang transform for detection and monitoring of crack in a transient rotor, Mechanical Systems and Signal Processing 22 (2008), 905-914.

[11] Y.Y He, D. Guo and F.L. Chu, Using genetic algorithms and finite element methods to detect shaft crack for rotor-bearing system, Mathematics and Computers in Simulation 57 (2001), 95-108.

[12] S.A. Adewusi and B.O. Al-Bedoor, Detection of propagating cracks in rotors using neural networks, Pipe and Component Analysis and Diagnosis 447 (2002), 71-78.

[13] K.M. Saridakis, A.C. Chasalevris, A.J. Dentsoras and C.A. Papadopoulos, Fusing neural networks, genetic algorithms and fuzzy logic for diagnosis of cracks in shafts, Intelligent production machines and systems: 2nd I*PROMS Virtual Conference, 3-14 July 2006.

[14] G Sabnavis, R.G Kirk, M. Kasarda and D. Quinn, Cracked shaft detection and diagnostics: a literature review, Shock and Vibration Digest 36 (2004), 287-296.

[15] P. Gardonio and M.J. Brennan, On the origins and development of mobility and impedance methods in structural dynamics, Journal of Sound and Vibration 249 (2002), 557-573.

[16] P. Bonello and M.J. Brennan, Modelling the dynamic behaviour of a supercritical rotor on a flexible foundation using the mechanical impedance technique, Journal of Sound and Vibration 239 (2001), 445-466.

[17] S. Prabhakar, A.S. Sekhar and A.R. Mohanty, Detection and monitoring of cracks using mechanical impedance of rotor-bearing system, The Journal of the Acoustical Society of America 110 (2001), 2351-2359.

[18] S. Prabhakar, A.R. Mohanty and A.S. Sekhar, Crack detection by measurement of mechanical impedance of a rotor-bearing system, The Journal of the Acoustical Society of America 112 (2002), 2825-2830.

[19] Y. Bamnios, E. Douka, A. Trochidis, Crack identification in beam structures using mechanical impedance, Journal of Sound and Vibration 256 (2002), 287-297.

[20] P. Gardonio, S.J. Elliott and R.J. Pinnington, Active isolation of structural vibration on a multiple-degree system, Part i: the dynamics of the system, Journal of Sound and Vibration 207 (1997), 61-93.

[21] R. Sheldon, Mechanical immittance- and transmission-Matrix concepts, The Journal of the Acoustical Society of America 41 (1967), 1171.

[22] S.T. Choi and S.Y. Mau, Dynamic analysis of geared rotor-bearing systems by the transfer matrix method, Journal of mechanical design 123 (2001), 562-568.

[23] J.J. Sinou and A.W. Lees, A non-linear study of a cracked rotor, European Journal of Mechanics/A Solids 26 (2007), 152-170.

[24] I.W. Mayes and W.G.R. Davies, Analysis of the response of a multi-rotor-bearing system containing a transverse crack in a rotor, Transactions of the ASME Journal of Vibration, Acoustics, Stress, and Reliability in Design 106 (1984), 139-145.

[25] J.J Sinou and A.W. Lees, Influence of cracks in rotating shafts, Journal of Sound and Vibration 285 (2005), $1015-1037$.

[26] C.A. Papadopoulos and A.D. Dimarogonas, Stability of cracked rotors in the coupled vibration mode, Journal of vibration, acoustics, stress, and reliability in design 110 (1988), 356-359.

[27] A.K. Darpe, K. Gupta and A. Chawla, Transient response and breathing behaviour of a cracked Jeffcott rotor, Journal of Sound and Vibration 272 (2004), 207-243.

[28] H.P.W. Gottlieb, Harmonic balance approach to limit cycles for nonlinear jerk equations, Journal of Sound and Vibration 297 (2006), 243-250.

[29] C.X. Mao and Q.H. Qin, Coupled torsional-flexural vibration of shaft systems in mechanical engineering. II: FE-TM impedance coupling method, Computers \& structures 58 (1996), 845-849.

[30] F. Chu and Z. Zhang, Bifurcation and chaos in a rub-impact Jeffcott rotor system, Journal of Sound and Vibration 210 (1998), 1-18. 

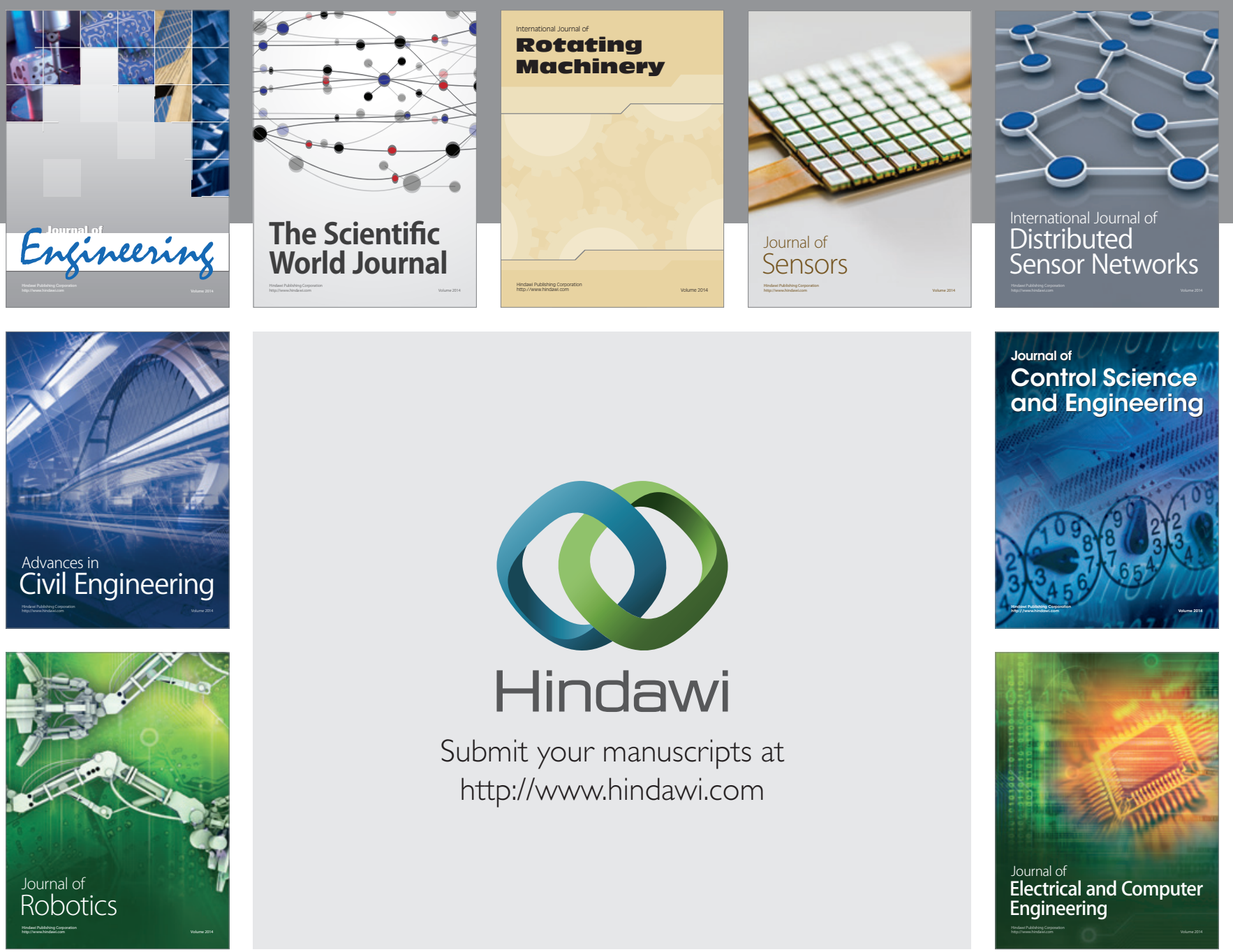

Submit your manuscripts at

http://www.hindawi.com
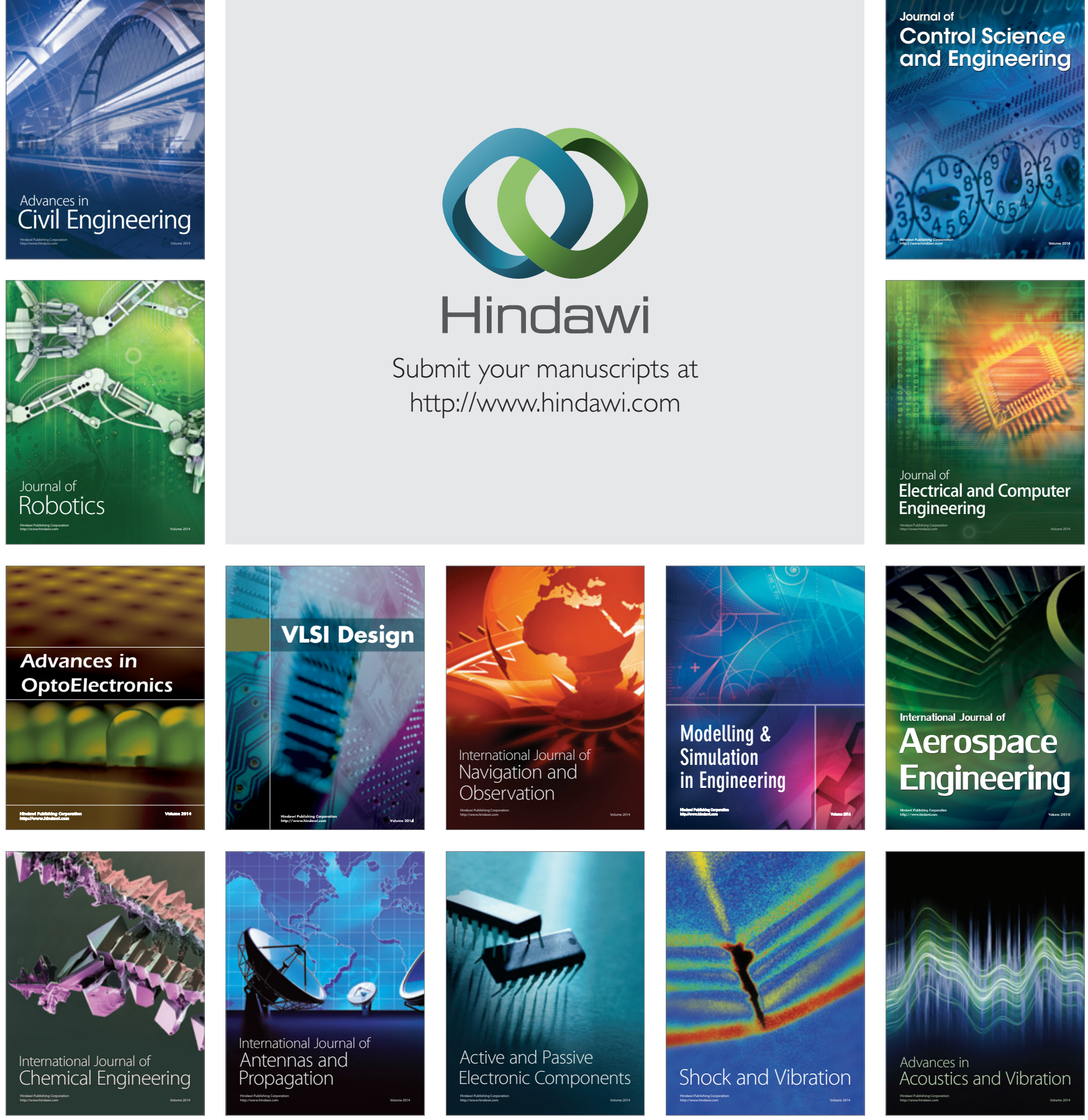